\title{
Üniversite Öğrencisi Algılarına Göre Yükseköğretim Kurumlarının Hizmet Kalitesinin İncelenmesi
}

\section{Muhammet İbrahim Akyürek*}

Öz

$\mathrm{Bu}$ araştırmanın amacı, lisans öğrencisi algısına göre yükseköğretim kurumlarının hizmet kalitesi düzeyini belirlemektir. Araştırma, kesitsel tarama modelindedir. Araştırmanın örneklemini, 2020-2021 öğretim yılında Türkiye’deki devlet üniversitelerinde öğrenim gören 460 lisans öğrencisi (birinci öğretim) oluşturmaktadır. Araştırmada Yükseköğretimde Hizmet Kalitesi Ölçeği kullanılmıştır. Araştırma verileri, 20202021 öğretim yılı Haziran ayı içerisinde elde edilmiştir. Araştırmada, öğrenci algılarına göre yükseköğretim kurumlarının hizmet kalitesinin orta düzeyde olduğu sonucuna ulaşılmıştır. Yükseköğretim kurumlarının hizmet kalitesi düzeyine ilişkin öğrenci algıları arasında sınıf değişkenine göre anlamlı bir şekilde farklılık olduğu; ancak cinsiyet değişkenine göre anlamlı bir farklılık olmadığı sonucuna ulaşılmıştır.

Anahtar Kelimeler: Yükseköğretim Kurumu, Hizmet Kalitesi, Lisans Öğrencisi.

* Dr., Etimesgut Bilim ve Sanat Merkezi, Ankara/Türkiye, i_akyurek56@hotmail.com, ORCID: 0000-0001-9122-471X 


\begin{abstract}
This research aims to determine how undergraduate students perceive the quality of services provided by higher education institutions. The study followed a cross-sectional scanning model. The sample of the research consists of 460 undergraduate students (primary education) attending state universities in Turkey during the 2020-2021 academic year. The Service Quality Scale in Higher Education was used in the research. Research data were obtained in June of the aforementioned academic year. Findings reveal that students perceivethe quality of services offered by higher education institutions to be moderate. There we observed a significant difference in students' perceptions by class level. However, no significant difference was found by gender.
\end{abstract}

Keywords: Higher Education Institution, Service Quality, Undergraduate Student.

\title{
Giriş
}

Ulusların vatandaşlarının beceri, bilgi ve küresel olarak rekabet etme kabiliyetlerini yaşadığımız küreselleşme çağına uygun şekilde geliştirmeleri gerekmektedir. Yükseköğretim kurumları küreselleşmenin etkilerini daha fazla hissetmektedir. Bu bağlamda, uluslararası iş deneyimi ve kısmen veya tamamen yurt dışında edinilmiş eğitim ihtiyacı artmaktadır (Lapina, Roga \& Müürsepp, 2016). Yükseköğretim kurumları; nitelikli insan kaynağı yetiştirilmesi ve bilimsel ilerleme yoluyla ülkelerine hizmet etmek sorumluluğu taşımaktadır. Eğitime yapılan yatırım, beşeri sermaye arzını artırmalı ve karşılığında verimli bir ekonomik büyüme kaynağı yaratmalıdır (Habib vd., 2019). Özellikle geçtiğimiz otuz yıl boyunca gerçekleştiği görülen teknolojik devrim, terörizm, artan rekabetçi iş piyasası ve nüfus artışı (Shahzad vd., 2019) gibi sosyal, politik ve ekonomik değişiklikler (Abbas, 2019) söz konusudur. Bu değişiklikler, imalat ve hizmet endüstrilerinin ihtiyaçlarını ve taleplerini değiştirmiştir (Imran \& Abbas, 2020). Ayrıca, yükseköğretim kurumlarının operasyonel koşullarını da etkileyen bu değişiklikler yükseköğretim kurumları ile çevreleri arasındaki kurulum ve ilişkilerde temel değişikliklere neden olmuştur (van Schalkwyk \& Steenkamp, 2016). Yükseköğretim düzenindeki önemli değişikliklerden bazıları; özel yükseköğretim kurumlarının sayısında sürekli bir artış, yükseköğretimin uluslararasılaşması (Abbas \& Sagsan, 2019), kamu yükseköğretim kurumları için devlet hibelerinde azalma ve kurumsal çeşitliliktir (Modestino vd., 2016). Bu sosyoekonomik değişiklikler, üniversite-toplum ilişkisinde ve istihdam gereksiniminde değişikliklere yol açmakla birlikte yükseköğretim kurumlarının yeni bilgi, uzmanlık, pedagoji ve finansman araçları bulmasına da sağlamaktadır (Abbas, 2020).

Eğitim kurumları, özellikle yükseköğretim kurumları, genç neslin yetiştirilmesinden (Brachem \& Braun, 2018) ve onları değerli kaynaklara dönüştürmekten sorumludur (Premand, Brodmann, Almeida, Grun \& Barouni, 2016). Yükseköğretimde genç neslin katılım oranındaki önemli artış (Roser \& Ortiz-Ospina, 2018), kamu yükseköğretim kurumlarının tüm öğrencileri 
barındıramamasıyla sonuçlanmış ve özel yükseköğretim kurumlarının önünü açmıştır. Sonuç olarak, son yirmi yılda dünya genelinde kamuya ait ve özel yüzlerce yeni yükseköğretim kurumu kurulmuştur (Acer \& Güçlü, 2017). Benzer şekilde, yükseköğrenimin uluslararasılaşması nedeniyle, her yıl binlerce öğrenci daha iyi eğitim almak için farklı ülkelere seyahat etmektedir (Jupiter vd., 2017). Bu gelişme, öğrenciler için yükseköğretim kurumu seçiminde, daha fazla alternatife ulaşılmasına imkân sağlamış ayrıca mevcut öğrencileri elde tutmak ve yeni öğrencileri çekebilmek için yükseköğretim kurumları arasındaki rekabeti de yoğunlaştırmıştır (Truong, Pham \& Vo, 2016). Hizmet kalitesi, rekabet gücünün önemli boyutlarından biridir ve pazarlama literatüründe geniş çapta incelenmektedir (Ali vd., 2016).

Mallara uygulanan kalite kavramı hizmet sektörüne genişletilemez (Parasuraman, Zeithaml \& Berry, 1985). Bunun nedeni, mallar kaliteyi anlamaya yönelik fiziksel ipuçlarına sahipken, hizmetlerdeki kalite ise "deneyim" ve "güven" faktörleri tarafından desteklenir. Ayrıca hizmetler performans odaklı, soyut, heterojen ve ayrılmaz olduğundan kaliteyi ölçmek zordur (Abili, Thani \& Afarinandehbin, 2012). Üstelik aynı kaliteyi tüm müşterilere her zaman sağlamak da kolay değildir. Araştırmacılar, hizmet kalitesinin, yükseköğretim kurumları için bile hayatta kalma, sürdürülebilirlik ve büyüme için en temel yeterlik olduğunu belirtmektedir (van Schalkwyk \& Steenkamp, 2014). Araştırmacılar ayrıca, yeni nesil öğrencilerin tüketici olarak daha fazla farkındalığa sahip olması, gelecek hakkında daha etkileşimli ve seçici olmaları dolayısıyla öğrencileri çekmenin daha zor hale geldiğini belirtmektedir (Zafiropoulos \& Vrana, 2008).

Son yirmi yılda, hizmet kalitesi kapsamlı bir şekilde araştırılmıştır (Moslehpour vd., 2020). Willms vd. (2006) hizmet kalitesinin doğasının, esas olarak hizmet sağlayıcı tarafından kontrol edilen performans ve fırsat kalitesine atıfta bulunduğunu öne sürmüştür. Kalite aynı zamanda inanç beyanları veya nitelik performansı olarak da ifade edilebilir ve ölçülebilir (Churchill \& Surprenant, 1982).

Hizmet kalitesi, bir hizmetin bir müşteri veya başka bir paydaş tarafından, "hizmet beklentileri karşılıyor mu/aşıyor mu, yani amaca uygun mu" bağlamında, genel olarak değerlendirilmesidir (Eshghi, Roy \& Ganguli, 2008). Bir hizmetin genel mükemmelliği veya üstünlüğü ile ilgili bir yargı veya tutumdur (Khodayari ve Khodayari, 2011). Basitçe ifade etmek gerekirse, algllanan hizmet kalitesi, bir hizmetin iyiliğinin veya kötülüğünün genel bir değerlendirmesidir (Twaissi ve Al-Kilani, 2015). Yüksek hizmet kalitesi sağlamak, sadece mevcut müşterileri elde tutmaya değil, aynı zamanda diğer paydaşlara, örneğin aday öğrenciler, işverenler, veliler, sponsorlar ve düzenleyiciler vb. tarafından verilen olumlu tavsiyelerin bir sonucu olarak yenilerini çekmeye de yardımcı olmaktadır (Ladhari, 2009; Negi, 2009). Bu, rekabetçi bir ortamda faaliyet gösteren üniversitelerin paydaşların ihtiyaçlarını karşılamak için yüksek kaliteli hizmeti nasıl sunacaklarını düşünmek zorunda olmalarını gerektirmektedir. (Deshields Jr., Kara \& Kaynak, 2005). Toplam eğitim deneyimlerinin kalitesi hakkında kurum çapında öğrenci geribildirimi, küresel olarak üniversitelerde artan bir faaliyet alanıdır (Cardona \& Bravo, 2012; Zineldin, 2007). 
Yükseköğretim kurum sayısındaki büyük artış, kaliteye yönelik kayda değer bir tehdidi göstergesi durumundadır (Ali vd., 2016). Yükseköğretim kurumlarının kuruluşundaki bu önemli artış, yükseköğretim kurumlarında kalite sorunu ile sonuçlanmıştır (Abbas, 2020). Örneğin Truong vd. (2016), özel üniversitelerdeki öğrencilerin çoğunun kendilerine sunulan altyapı ve olanakların kalitesinden memnun olmadığını belirtmiştir. Mok \& Jiang (2017), yükseköğretimin kitleselleşmesi nedeniyle, dünyanın dört bir yanındaki bazı yükseköğretim kurumlarının, öğrencilere uygun eğitim verilmesi ve yükseköğretim kurumlarındaki tesis ile donanımların mevcudiyeti gibi durumlarda kaliteden ödün verdiğini ifade etmiştir.

Günümüzde son derece rekabetçi ve dinamik olarak değişen küresel pazarda, yükseköğretim kurumları sadece kültürel ve sosyal kalkınmada yükseköğretim kurumu rolünü oynamakla kalmamakta, aynı zamanda ulusal ekonomide de önemli bir rol oynamaktadır (Abbas \& Sagsan, 2019). Bu nedenle, yükseköğretim kurumları yavaş yavaş iş benzeri organizasyonlara dönüşmekte ve hesap verebilirlik ile kalite güvencesi için performans göstergelerine sahip olmaktadır (Brachem \& Braun, 2018). Yükseköğretim kurumları günümüzde pazar odaklı ticari işletmelere dönüşme eğilimindedir ve hizmet kalitesi kuruluşun kendisi tarafından değil müşteriler tarafından tanımlanmaktadır bu nedenle, müşterilerin kalite ve memnuniyet algısı ile daha fazla ilgilenmeleri gerekmektedir (Li, 2018). Müşterilerin hizmet kalitesinden memnuniyeti organizasyonel başarının belirleyicilerinden biridir (Abbas, 2019; Campos, Santos \& Castro, 2017). Öğrenciler, yükseköğretim kurumlarının birincil hizmet edilmesi gereken unsurlarındandır, bu nedenle memnuniyetleri sağlanmalıdır (Guilbault, 2018). Bununla birlikte, Guilbault (2018) ve Tholen, Relly, Warhurst ve Commander (2016) gibi bir dizi araştırmacı, öğrencileri müşteri ve eğitim kurumlarını iş benzeri kuruluşlar olarak görmeye karşı çıkmıştır. Liu (2016), öğrencilerin hizmet edilmesi gereken bir unsur olarak kabul edilmesi durumunda, yükseköğretim kurumlarının onlara istediklerini vermeleri gerektiğini ve bu durumun eğitimde kalite sunumu ile çelişebileceğini belirtmiştir.

Genel olarak, farklı hizmet endüstrileri ve sektörleri ile ilgili olarak hizmet kalitesi üzerine bir literatür hakimdir. Hizmet kalitesinin doğru tanımlanması ve nasıl ölçülmesi gerektiği konusunda araştırmacılar arasında tartışmalar olmuştur. Örneğin araştırmalar, yükseköğretim kurumlarında "hizmet kalitesi” tanımı konusunda bir fikir birliğinin olmadığını göstermektedir ki bu da ölçüm metodolojilerinde tartışmalara yol açmaktadır (Doherty, 2008; Brochado, 2009). Bu nedenle, hizmet kalitesini değerlendirmek için bir dizi hizmet kalitesi çerçevesi kullanılmaktadır. Üniversitelerde hizmet kalitesini değerlendirmek için, bazı çalışmalarda (Gerşil \& Güven, 2018; Türeli \& Aytar, 2014; Yllmaz, Filiz \& Yaprak, 2007) Parasuraman, Zeithaml ve Berry (1988) tarafından geliştirilen SERVQUAL (Hizmet Kalitesi) modeli kullanılmıştır. Yazarlara göre hizmet kalitesi; güvenilirlik, güvence, dokunulurluk, empati ve duyarlılık olmak üzere beş temel boyuta odaklanarak ölçülebilir (Parasuraman, Zeithaml \& Berry, 1988). Ardından Cronin ve Taylor (1992) tarafından SERVPERF modeli geliştirilmiştir. SERVPERF modeli hizmet kalitesini algılamanın bir fonksiyonu olarak değerlendirerek ölçeğin tek boyutlu olduğunu öne sürmektedir (Cronin \& Taylor, 1992). Yükseköğretim kurumlarında hizmet kalitesi ile 
ilgili olarak Firdaus (2005) tarafından geliştirilmiş HEdPERF ölçeği de yer almaktadır. HEdPERF ölçeği; hizmet kalitesini yükseköğretim kurumunun akademik olmayan özellikleri, akademik özellikleri, erişilebilirliği, imajı, sunduğu programlar ve empati kurabilme yeteneği olmak üzere altı boyutta incelemektedir (Firdaus, 2005). Daha yakın zamanlarda, üniversite hizmet kalitesinin değerlendirilmesinde arayışlar artmış ve bu kapsamda yeni çerçeveler sunulmuştur. İçli ve Anıl (2014), yükseköğretim kurumlarında hizmet kalitesini ölçmek için HEDQUAL adlı yeni bir ölçek önermiştir. Ölçek; akademik kalite, idari hizmet kalitesi, kütüphane hizmet kalitesi, kariyer fırsatları sağlama kalitesi ve destek hizmetleri olmak üzere beş temel boyuta odaklanmaktadır (İçli \& Anıl, 2014). Son olarak, Zineldin (2007) 5Q adlı bir çerçeve önermiştir. $\mathrm{Bu}$; nesnenin kalitesi, sürecin kalitesi, altyapının kalitesi, etkileşim ve iletişimin kalitesi ile atmosferin kalitesi olmak üzere beş temel boyutu içermektedir (Zineldin, 2007; Zineldin, Akdag \& Vasicheva, 2011). Bu çalışma ise Çınkır, Yıldız ve Kurum (2021) tarafından geliştirilen "Yükseköğretimde Hizmet Kalitesi Ölçeği”nde yer alan üç boyut (akademik hizmetler, idari hizmetler ve kampüs olanakları) üzerine kurgulanmıştır. Bu ölçeğin, benzerlerine göre tercih edilmesi; değişen ve gelişen küresel atmosferdeki yükseköğretim kalite standartlarına cevap niteliğinde olabilecek güncelliğinden kaynaklanmaktadır.

Öğrencilerin öğrenim gördükleri kuruma dönük olarak kalite beklentileri çok boyutlu bir olgu olup; fiziki mekânlar, eğitim kalitesi, sosyal kültürel ve sportif olanaklar, öğrencinin bireysel özellikleri, sunulan uygulama olanakları gibi farklı boyutları kapsamaktadır (Saydan, 2008). Öğrencilerin bu konularla ilgili deneyimlerine ilişkin görüşlerine başvurmak yükseköğretimde kalite güvencesinin oluşturulması için kullanılan temel araçlardan biri olmuştur (Zineldin, Akdag \& Vasicheva, 2011). Bu çerçevede yükseköğretim hizmetinin en önemli alıcısı durumunda olan öğrencilerin onlara sunulan olanak ve hizmetlere ilişkin memnuniyet, beklenti ve kalite algılarının belirlenmesi yükseköğretim kalitesinin artırılması bakımından önemlidir (Donalds \& Denison, 2001; İçli \& Vural, 2010; Watty, 2006).

Yükseköğretimde hizmet kalitesinin belirlenmesi, üniversitelerin kendilerini geliştirmelerine rehberlik edebilecektir. Türkiye'de bu konuda yapılan çalışmalar incelendiğinde; sınırlı ve aynı zamanda bir üniversite özelinde (Çınkır, Yıldız \& Kurum, 2021; Gerşil \& Güven, 2018; Türeli \& Aytar, 2014) veya bir fakülte özelinde (Yllmaz, Filiz \& Yaprak, 2007) gerçekleştirildiği görülmektedir. Ayrıca yükseköğretimde hizmet kalitesinin Türkiye genelindeki durumunun belirlenmesinin alanyazında bir ihtiyaç olduğu ifade edilebilir. Yükseköğretim kurumlarının hizmet kalitesi bağlamında akademik ve idari hizmetler ile kampüs olanaklarının Türkiye genelindeki durumunu incelemek, bütüncül bir bakış açısı kazandırabilecek ve alanyazındaki bu ihtiyaca cevap verebilecektir. Bu nedenle araştırma, Türkiye genelindeki yükseköğretim kurumlarının hizmet kalitesini belirlemeye yöneliktir. Ayrıca yapılan araştırmalar, gerçekleştirildiği zamanın kalite standartlarına ilişkin ölçümlerle hizmet kalitesini belirlemiştir. Bu araştırma ise değişen ve gelişen bir küresel atmosferin kalite standartlarına cevap niteliğinde olabilecek güncel bir ölçek (Çınkır, Yıldız \& Kurum, 2021) aracılığıyla gerçekleştirilmiştir. Müşterilerin 
hizmet kalitesinden memnuniyeti organizasyonel başarının belirleyicilerinden biridir (Abbas, 2019; Campos, Santos \& Castro, 2017). Öğrenciler, yükseköğretim kurumlarının en önemli hizmet edilmesi gereken varlıkları arasında bulunduğundan memnuniyetlerinin sağlanması gereklidir (Guilbault, 2018). Toplam eğitim deneyimlerinin kalitesi hakkında kurum çapında öğrenci geribildirimi, küresel olarak üniversitelerde artan bir faaliyet alanıdır (Cardona \& Bravo, 2012; Zineldin, 2007). Yükseköğretimde hizmet kalitesinin, kalitenin iyileştirilmesine ve geliştirilmesine ilişkin olarak birincil müşteri olarak kabul edilen ve geribildirimine önem verilen öğrenci algılarına göre belirlenmesi önemlidir. Yükseköğretimde hizmet kalitesinin ölçümü ve belirlenmesi yoluyla yükseköğretimde gelişim ve başarının daha fazla sağlanması mümkün olabilecektir. Bu bağlamda araştırmanın amacı, lisans öğrencisi algısına göre yükseköğretim kurumlarının hizmet kalitesi düzeyini belirlemektir. Bu doğrultuda belirlenen alt problemler şunlardır:

1. Lisans öğrencisi algısına göre yükseköğretim kurumlarının hizmet kalitesi ne düzeydedir?

2. Yükseköğretim kurumlarının hizmet kalitesi düzeyine ilişkin lisans öğrencisi algıları, bazı demografik değişkenlere (cinsiyet, sınıf) göre farklılık göstermekte midir?

\section{Yöntem}

\section{Araştırmanın Modeli}

Araştırma, nicel araştırma yöntemleri arasında yer alan kesitsel tarama modelindedir. Tarama modelinde, araştırmadaki birey ya da konu bulunduğu koşullar içinde olduğu gibi betimlenmeye çalışılır (Karasar, 2015). Kesitsel tarama modelinde, betimlenecek değişkenler (tutum gibi) bir seferde ölçülür. Bu model kapsamında, lisans öğrencisi algısına göre yükseköğretim kurumlarının hizmet kalitesi düzeyi tek seferde ölçülerek belirlenmeye çalışılmıştır.

\section{Evren ve Örneklem}

Araştırmanın evrenini, 2020-2021 öğretim yılında Türkiye'deki devlet üniversitelerinde öğrenim gören lisans öğrencileri (birinci öğretim) oluşturmaktadır. Yükseköğretim Kurulu (YÖK) 20192020 Öğretim Yllı İstatistikleri'ne göre toplam 127 Devlet Üniversitesi’nde öğrenim gören lisans öğrencisi (birinci öğretim) sayısı 815781'dir.

Sayısı belli olan evrenden hareketle örneklem hesabı şu şekildedir:

$\mathbf{N}=815781, \mathbf{p}=0.5, \mathbf{q}=0.5, \mathrm{t}=1.96, \mathbf{d}=0.05, \mathbf{n}=$ ?

$$
\mathrm{N} \mathrm{t}^{2} \mathrm{pq} \quad 815781 \times(1.96)^{2} \mathrm{x} \quad 783476.0724
$$

$0.5 \times 0.5$

$\begin{aligned} \mathbf{n}=\frac{\mathrm{d}^{2}(\mathrm{~N}-1)+\mathrm{t}^{2} \mathrm{p} \mathrm{q}}{=} & \left.\frac{}{(0.05)^{2} \mathrm{x}(815781-}=\frac{\mathbf{3 8 4}}{2040.4104}=\quad=\quad 1\right)+(1.96)^{2} \times 0.5 \mathrm{x} \\ & 0.5\end{aligned}$


Değerler, formülde yerlerine yazıldığında; $n=384$ olarak elde edilmektedir. Buna göre çalışmanın örneklem büyüklüğü için alt sınır 384'tür. Araştırmanın örneklemini, 2020-2021 öğretim yılında Türkiye'deki 21 devlet üniversitesinde öğrenim gören 460 lisans öğrencisi (birinci öğretim) oluşturmaktadır. Bu çalışmadaki evrene göre örneklem sayısı \%95 güven aralığına göre yeterlidir (Gürbüz \& Şahin, 2014). Öğrencilerin örnekleme alınması, seçkisiz örnekleme yöntemleri arasında yer alan basit seçkisiz örnekleme ile gerçekleştirilmiştir. Seçkisizlik, örneklemede temel alınan birimlerin örneklem için seçilme ihtimallerinin eşit olmasını ifade eder (Büyüköztürk, Çakmak, Akgün, Karadeniz \& Demirel, 2012).

Aşağıdaki tabloda, katılımcı öğrencilerin demografik değişkenlerine (cinsiyet, sınıf) ilişkin betimsel istatistiklere yer verilmiştir.

Tablo 1. Katılımcı Öğrencilerin Demografik Değişkenlerine İlişkin Betimsel İstatistikler

\begin{tabular}{|c|c|c|c|}
\hline Değişkenler & Sinif & $\mathbf{N}$ & $\%$ \\
\hline & $\mathrm{K} ı \mathrm{Z}$ & 336 & 73.0 \\
\hline \multicolumn{4}{|l|}{ Cinsiyet } \\
\hline & Erkek & 124 & 27.0 \\
\hline & Hazırlık sınıfı & 12 & 2.6 \\
\hline & 1.sinif & 104 & 22.6 \\
\hline \multirow[t]{3}{*}{ Sinif } & 2.sinif & 228 & 49.6 \\
\hline & 3.sinif & 80 & 17.4 \\
\hline & 4.sinif & 36 & 7.8 \\
\hline Toplam & & 460 & 100 \\
\hline
\end{tabular}

Tablo incelendiğinde; cinsiyet değişkenine göre kız öğrencilerin \%73 ile, erkek öğrencilere göre daha fazla olduğu görülmektedir. Sınıf değişkenine göre ise en fazla orana sahip grubu \%49.6 ile 2.sınıf, en az orana sahip grubu ise \%2.6 ile hazırlık sınıfı öğrencileri oluşturmaktadır.

\section{Veri Toplama Araçları}

Araştırmada Çınkır, Yıldız ve Kurum (2021) tarafından geliştirilen "Yükseköğretimde Hizmet Kalitesi Ölçeği” kullanılmıştır. Ölçek beşli likert tipinde 29 maddeden oluşmakta ve üç boyutlu bir yapıdadır. Ölçeğin yapı geçerliğini test etmek amacıyla kullanılan öncelikle Açımlayıcı Faktör Analizi (AFA) yapılmış ve varyansın \%45.04’ü açıklanmıştır. Sonrasında yapılan Doğrulayıcı Faktör Analizi (DFA) ile ölçeğin dört boyutlu yapısı doğrulanmıştır, maddelerinin faktör yükleri ise .48 ile .72 arasında değişmiştir. Ayrıca doğrulayıcı faktör analizi sonucu oluşan uyum iyiliği değerleri $\mathrm{x}^{2} / \mathrm{sd}=8.28$; RMSEA=.46; SRMR=.04; CFI= .91 ve TLI= .90 olarak 
elde edilmiştir. Güvenirlik analiz sonucu, ölçeğin güvenirlik katsayısı .89 bulunmuştur ve madde toplam korelasyon değerlerinin ise .38 ile .60 arasında değiştiğini göstermiştir (Çınkır, Yıldız \& Kurum, 2021). Böylece, uyarlanan Yükseköğretimde Hizmet Kalitesi Ölçeğinin geçerli ve güvenilir olduğu belirlenmiştir. Yükseköğretimde hizmet kalitesi ölçeğinde "akademik hizmetler" boyutu 1-15 (örnek madde; fakültemden aldığım eğitimin beklenti-ihtiyaçlarımı karşılamasından...); "idari hizmetler” boyutu 16-21 (örnek madde; kütüphane koleksiyonları/ veri tabanlarının akademik ihtiyaçlarımızı karşılamasından...); "kampüs olanakları" boyutu 22-29 (örnek madde; kampüsteki yemekhane olanaklarından...) arasındaki maddelerle ölçülmektedir. Ölçeğin madde kod ve aralıkları; "hiç memnun değilim" (1; 1.00-1.80), "memnun değilim" (2; 1.81-2.60), "ne memnunum ne de değilim" (3; 2.61-3.40), "memnunum" (4; 3.41-4.20), “çok memnunum” (5; 4.21-5.00) şeklinde belirtilmiştir.

Bu çalışmada, istatistiksel program aracılığıyla hesaplanan ölçeğin Cronbach Alfa güvenirlik katsayısı .96 olarak bulunmuştur. Psikolojik test için hesaplanan güvenirlik katsayısının .70 ve daha fazla olması test puanlarının güvenirliği için genel bağlamda yeterli görülmektedir (Büyüköztürk, 2013).

\section{Verilerin Toplanması ve Analizi}

Araştırmada kullanılan ölçme aracı, 2020-2021 öğretim yılı Haziran ayı içerisinde, Türkiye’deki devlet üniversitelerinde öğrenim gören 460 lisans öğrencisine (birinci öğretim) dijital ortamda (pandemi nedeniyle, veri toplama döneminde, üniversitelerde uzaktan eğitim yapıldı̆̆ından ve buna bağlı olarak üniversitelerde öğrenci bulunmadığı için veriler yüz yüze toplanamamıştır) uygulanarak veriler elde edilmiştir. Verilerin analizi kapsamında öncelikle veri setinin normallik varsayımını karşılama durumu incelenmiştir. Bu doğrultuda basıklık ve çarpıklık katsayıları ile ortalama, mod ve medyan değerlerine bakılmıştır. Ölçeğin geneli ve boyutlar bazında hesaplanan sırasıyla basıklık, çarpıklık ve standart sapma değerleri şu şekildedir: ölçeğin geneli .93, -1.16, .75; akademik hizmetler boyutu .32, -1.02, .83; idari hizmetler boyutu .07, -.50, .87; kampüs olanakları boyutu -.05, -.67, .81. Çalışmadaki basıklık ve çarpıklık değerleri \pm 2 arasında yer almaktadır. Bu sonuçlar veri setinin normal dağılım gösterdiği biçiminde yorumlanmaktadır (George \& Mallery, 2010). Ayrıca yapılan analizlerde aritmetik ortalamanın 3.08, mod değerinin 3.38 ve medyanın 3.31 olduğu tespit edilmiştir. Bu değerlerin birbirine yakın olması da veri setinin normal dağıldığını göstermektedir (Hair, Ringle \& Sarstedt, 2011). Veri setinin normallik varsayımını sağlamış olması nedeniyle güvenirlik analizi için Cronbach Alfa iç tutarlılık katsayısı tekniğinden yararlanılmasına karar verilmiştir (Gravetter \& Walnau, 2000). Bu bağlamda, araştırmanın alt problemlerinin sınanması için parametrik ve parametrik olmayan test teknikleri seçilerek kullanılmıştır. Bu kapsamda verilerin çözümlenmesi kapsamında öncelikle yüzde ve frekans analizleri yapılmıştır. Parametrik istatistik olarak, iki alt kategorili değişkenlerde, bağımsız örneklemler için t-testi uygulanmıştır. Bazı alt problemlerde; alt gruplarda yer alan katılımcı sayısının az (15’ten küçük) olması, puanların normal dağılımını engellemektedir. Bu nedenle parametrik olmayan istatistiğin kullanılması 
zorunluluktur (Büyüköztürk, 2013). Araştırmada, bu alt problemlere dönük olarak grupların ortalamaları arasındaki karşılaştırmalar, normallik varsayımını gerektirmeyen Kruskal Wallis-H testi kullanılarak gerçekleştirilmiştir; analiz sonucunda ortaya çıkan anlamlı farklılıkların hangi gruplar arasında olduğunu bulmaya dönük olarak da Mann Whitney U-testi uygulanmıştır. Bulguların yorumlanmasında, anlamlılık değeri $\mathrm{p}<.05$ olarak esas alınmıştır.

\section{Bulgular}

Araştırmanın birinci alt problemi kapsamında; lisans öğrencisi algılarına göre yükseköğretim kurumlarının hizmet kalitesi düzeyi incelenmiştir. Aşağıdaki tabloda, öğrenci algılarına göre yükseköğretim kurumlarının hizmet kalitesi düzeyine ilişkin betimsel istatistiklere yer verilmiştir.

Tablo 2. Öğrenci Algılarına Göre Yükseköğretim Kurumlarının Hizmet Kalitesi Düzeyine ìlişkin Betimsel İstatistikler

\begin{tabular}{lccc}
\hline Boyutlar & $\mathbf{N}$ & $\bar{\chi}$ & SS \\
\hline Akademik Hizmetler & 460 & 3.15 & .83 \\
\cline { 2 - 4 } İdari Hizmetler & 460 & 3.07 & .87 \\
\cline { 2 - 4 } Kampüs Olanakları & 460 & 2.97 & .81 \\
\cline { 2 - 4 } & & 3.08 & .75 \\
\hline
\end{tabular}

Tablo incelendiğinde; öğrenci algılarına göre yükseköğretim kurumlarının hizmet kalitesinin "ne memnunum ne de değilim" düzeyinde ( $\bar{\chi}=3.08)$ olduğu görülmektedir. Ayrıca boyutlar bazında, öğrenci algılarına göre yükseköğretim kurumlarının hizmet kalitesi incelendiğinde ise akademik hizmetler $(\bar{\chi}=3.15)$, idari hizmetler $(\bar{\chi}=3.07)$ ve kampüs olanakları $(\bar{\chi}=2.97)$ boyutlarında "ne memnunum ne de değilim" düzeyinde olduğu görülmektedir. Boyutlar incelendiğinde; öğrenci algılarına göre yükseköğretim kurumlarının hizmet kalitesi düzeyi en yüksek boyut akademik hizmetler, en düşük boyut ise kampüs olanakları olmuştur.

Araştırmanın ikinci alt problemi kapsamında; yükseköğretim kurumlarının hizmet kalitesi düzeyine ilişkin lisans öğrencisi algıları, bazı demografik değişkenlere (cinsiyet, sınıf) göre incelenmiştir. 
Tablo 3. Cinsiyet Değişkenine Göre, Yükseköğretim Kurumlarının Hizmet Kalitesi Düzeyine İlişkin T-Testi Sonuçları

\begin{tabular}{|c|c|c|c|c|c|c|c|}
\hline Boyutlar & Cinsiyet & $N$ & $\bar{\chi}$ & SS & sd & $t$ & $p$ \\
\hline \multirow{3}{*}{ Akademik Hizmetler } & $\mathrm{K} 1 \mathrm{z}$ & 336 & 3.19 & .81 & \multirow{3}{*}{458} & \multirow{3}{*}{1.95} & \multirow{3}{*}{.052} \\
\hline & & & & & & & \\
\hline & Erkek & 124 & 3.02 & .88 & & & \\
\hline \multirow{3}{*}{ İdari Hizmetler } & $\mathrm{K} 1 \mathrm{z}$ & 336 & 3.12 & .87 & \multirow{3}{*}{458} & \multirow{3}{*}{1.98} & \multirow{3}{*}{$.048^{*}$} \\
\hline & & & & & & & \\
\hline & Erkek & 124 & 2.94 & .84 & & & \\
\hline \multirow{3}{*}{ Kampüs Olanakları } & $\mathrm{K} 1 \mathrm{z}$ & 336 & 2.98 & .82 & \multirow{3}{*}{458} & \multirow{3}{*}{.48} & \multirow{3}{*}{.625} \\
\hline & & & & & & & \\
\hline & Erkek & 124 & 2.94 & .75 & & & \\
\hline \multirow{2}{*}{$\begin{array}{l}\text { Yükseköğretimde } \\
\text { Hizmet Kalitesi (Genel) }\end{array}$} & $\mathrm{K} 1 \mathrm{Z}$ & 336 & 3.12 & .73 & \multirow{2}{*}{458} & \multirow{2}{*}{1.75} & \multirow{2}{*}{.080} \\
\hline & Erkek & 124 & 2.98 & .76 & & & \\
\hline
\end{tabular}

${ }^{*} \mathrm{p}<.05$

Tablo incelendiğinde; yükseköğretim kurumlarının hizmet kalitesi düzeyi, öğrencilerin cinsiyet değişkenine göre anlamlı bir farklılık göstermemektedir, t (458)= 1.75, p> .05.

Boyutlar bazında, yükseköğretim kurumlarının idari hizmetler kalitesi düzeyi, öğrencilerin cinsiyet değişkenine göre anlamlı bir farklılık göstermektedir, $\mathrm{t}(458)=1.98, \mathrm{p}<.05$. Kız öğrenciler $(\bar{\chi}=3.12-$ "ne memnunum ne de değilim" düzeyinde), erkek öğrencilere ( $\bar{\chi}=2.94$-"ne memnunum ne de değilim" düzeyinde) göre yükseköğretim kurumlarının idari hizmetler kalitesi düzeyini daha yüksek olarak belirtmiştir. Ayrıca yükseköğretim kurumlarının akademik hizmetler ve kampüs olanakları kalitesi düzeyi, öğrencilerin cinsiyet değişkenine göre anlamlı bir farklılık göstermemektedir. Akademik hizmetler boyutu, t $(458)=1.95$, p> .05; kampüs olanakları boyutu, $\mathrm{t}(458)=.48, \mathrm{p}>.05$. 
Tablo 4. Sınıf Değişkenine Göre, Yükseköğretim Kurumlarının Hizmet Kalitesi Düzeyine İlişkin Kruskal Wallis-H Testi Sonuçları

\begin{tabular}{|c|c|c|c|c|c|c|c|}
\hline Boyut & Sinif & $N$ & $\begin{array}{l}\text { Sira } \\
\text { Ort. }\end{array}$ & sd & $\chi^{2}$ & $p$ & $\begin{array}{c}\text { Anlaml } \\
\text { Fark }\end{array}$ \\
\hline \multirow{5}{*}{ Akademik Hizmetler } & Hazırlık sınıfı(1) & 12 & 305.17 & \multirow{5}{*}{4} & \multirow{5}{*}{14.540} & \multirow{5}{*}{$.006^{*}$} & \multirow{5}{*}{$\begin{array}{l}1-3,1-5 \\
2-3,2-5\end{array}$} \\
\hline & $1 . \sin 1 f(2)$ & 104 & 260.35 & & & & \\
\hline & 2.sinif(3) & 228 & 217.94 & & & & \\
\hline & 3.sinif(4) & 80 & 234.60 & & & & \\
\hline & $4 . \sin 1 f(5)$ & 36 & 189.83 & & & & \\
\hline \multirow{5}{*}{ İdari Hizmetler } & Hazırlık sinıfı(1) & 12 & 331.83 & & & & \multirow{5}{*}{$\begin{array}{l}1-2,1-3, \\
1-4,3-2 \\
4-2,4-3 \\
5-2,5-3\end{array}$} \\
\hline & 1.sinif(2) & 104 & 193.27 & & & & \\
\hline & $2 . \sin 1 f(3)$ & 228 & 224.54 & 4 & 23.819 & $.000^{*}$ & \\
\hline & $3 . \sin 1 f(4)$ & 80 & 261.90 & & & & \\
\hline & $4 . \sin 1 f(5)$ & 36 & 272.28 & & & & \\
\hline \multirow{5}{*}{ Kampüs Olanakları } & Hazırlık sınıfı(1) & 12 & 390.50 & & & & \multirow{5}{*}{$\begin{array}{c}1-2,1-3 \\
1-4,1-5 \\
5-2,5-3 \\
5-4\end{array}$} \\
\hline & $1 . \sin 1 f(2)$ & 104 & 226.12 & & & & \\
\hline & 2.sinif(3) & 228 & 219.24 & 4 & 28.755 & $.000^{*}$ & \\
\hline & $3 . \sin 1 f(4)$ & 80 & 215.30 & & & & \\
\hline & 4.sinif(5) & 36 & 294.94 & & & & \\
\hline \multirow{5}{*}{$\begin{array}{l}\text { Yükseköğretimde } \\
\text { Hizmet Kalitesi } \\
\text { (Genel) }\end{array}$} & Hazırlık sinıfı(1) & 12 & 371.17 & & & & \multirow{5}{*}{$\begin{array}{l}1-2,1-3 \\
1-4,1-5\end{array}$} \\
\hline & 1.sinif(2) & 104 & 232.19 & & & & \\
\hline & $2 . \sin 1 f(3)$ & 228 & 218.36 & 4 & 15.915 & $.003^{*}$ & \\
\hline & $3 . \sin 1 f(4)$ & 80 & 241.40 & & & & \\
\hline & 4.sinif(5) & 36 & 231.39 & & & & \\
\hline
\end{tabular}

${ }^{*} \mathrm{p}<.05$

Tablodaki analiz sonuçları; öğrencilerin yükseköğretim kurumlarının hizmet kalitesine ilişkin algılarının, sınıf değişkenine göre anlamlı bir şekilde farklılaştığını göstermektedir, 
$\mathrm{X}^{2}(s d=4, N=460)=15.915, p<.05$. Bu bulgu; sınıfın, öğrencilerin yükseköğretim kurumlarının hizmet kalitesi algılarında farklı etkilere sahip olduğunu gösterir. Grupların sıra ortalamaları dikkate alındığında, öğrencilerin yükseköğretim kurumlarının hizmet kalitesi algısı en yüksek "hazırlık sınıfı", en düşük ise "2. sınıf” grupları oluşturmaktadır. Anlamlı farklılıkların hangi gruplar arasında olduğunu bulmaya dönük olarak Mann Whitney U-testi uygulanmıştır. Analiz sonucunda sıra ortalamaları dikkate alındığında, hazırlık sınıfı öğrencileri, 1., 2., 3. ve 4. sınıf öğrencilerine göre yükseköğretimde hizmet kalitesi düzeyini daha yüksek olarak algılamıştır. Boyutlar bazında analiz sonuçları; öğrencilerin yükseköğretim kurumlarının akademik hizmetler kalitesine ilişkin algılarının, sınıf değişkenine göre anlamlı bir şekilde farklılaştığını göstermektedir, $\mathrm{x}^{2}(s d=4, N=460)=14.540, p<.05$. Bu bulgu; sınıfın, öğrencilerin yükseköğretim kurumlarının akademik hizmetler kalitesi algılarında farklı etkilere sahip olduğunu gösterir. Grupların sıra ortalamaları dikkate alındığında, öğrencilerin yükseköğretim kurumlarının akademik hizmetler kalitesi algısı en yüksek "hazırlık sınıfı", en düşük ise "4.sınıf" grupları oluşturmaktadır. Anlamlı farklılıkların hangi gruplar arasında olduğunu bulmaya dönük olarak Mann Whitney U-testi uygulanmıştır. Analiz sonucunda sıra ortalamaları dikkate alındığında, hazırlık sınıfı ile 1. sınıf öğrencileri, 2. ve 4. sınıf öğrencilerine göre yükseköğretimde akademik hizmetler kalitesi düzeyini daha yüksek olarak algılamıştır.

Analiz sonuçları; öğrencilerin yükseköğretim kurumlarının idari hizmetler kalitesine ilişkin algılarının, sınıf değişkenine göre anlamlı bir şekilde farklılaştığını göstermektedir, $\mathrm{x}^{2}(s d=4, N=$ 460) $=23.819, p<.05$. Bu bulgu; sınıfın, öğrencilerin yükseköğretim kurumlarının idari hizmetler kalitesi algılarında farklı etkilere sahip olduğunu gösterir. Grupların sıra ortalamaları dikkate alındığında, öğrencilerin yükseköğretim kurumlarının idari hizmetler kalitesi algısı en yüksek "hazırlık sınıfı", en düşük ise "1.sınıf" grupları oluşturmaktadır. Anlamlı farklılıkların hangi gruplar arasında olduğunu bulmaya dönük olarak Mann Whitney U-testi uygulanmıştır. Analiz sonucunda sıra ortalamaları dikkate alındığında, hazırlık sınıfı öğrencileri, 1., 2. ve 3. sınıf öğrencilerine; 2. sınıf öğrencileri, 1. sınıf öğrencilerine; 3. sınıf ile 4. sinıf öğrencileri, 1. ve 2. sınıf öğrencilerine göre yükseköğretimde idari hizmetler kalitesi düzeyini daha yüksek olarak algılamıştır.

Ayrıca analiz sonuçları; öğrencilerin yükseköğretim kurumlarının kampüs olanakları kalitesine ilişkin algılarının, sınıf değişkenine göre anlamlı bir şekilde farklılaştığını göstermektedir, $\mathrm{x}^{2}(s d=4, N=460)=28.755, p<.05$. Bu bulgu; sınıfın, öğrencilerin yükseköğretim kurumlarının kampüs olanakları kalitesi algılarında farklı etkilere sahip olduğunu gösterir. Grupların sıra ortalamaları dikkate alındığında, öğrencilerin yükseköğretim kurumlarının kampüs olanakları kalitesi algısı en yüksek "hazırlık sınıfı", en düşük ise "3.sınıf" grupları oluşturmaktadır. Anlamlı farklılıkların hangi gruplar arasında olduğunu bulmaya dönük olarak Mann Whitney U-testi uygulanmıştır. Analiz sonucunda sıra ortalamaları dikkate alındığında, hazırlık sınıfı öğrencileri, 1., 2., 3. ve 4. sınıf öğrencilerine; 4. sınıf öğrencileri, 1., 2. ve 3. sınıf öğrencilerine göre yükseköğretimde kampüs olanakları kalitesi düzeyini daha yüksek olarak algılamıştır. 


\section{Tartışma, Sonuç ve öneriler}

Araştırmanın birinci alt problemi kapsamında; lisans öğrencisi algılarına göre yükseköğretim kurumlarının hizmet kalitesi düzeyi incelenmiştir. Öğrenci algılarına göre yükseköğretim kurumlarının hizmet kalitesinin orta düzeyde olduğu sonucuna ulaşılmıştır. Bu durum, yükseköğretim kurumlarında öngörülen hizmetlerin daha nitelikli olması gerektiğine ve kaliteli bir hizmet anlayışı gereksinimine işaret edebilir. Çünkü öğrenci algılarına bakıldığında yükseköğretim kurumlarındaki hizmet kalitesinin yeterli olmadığı görülmektedir. Yükseköğretim kurumlarının hizmet kalitesinin orta düzeyde olduğuna ilişkin araştırma bulgusu; Arakaya (2016), Aygün (2015), Gerşil ve Güven (2018) ile Özçelik (2018) tarafından yapılan araştırma bulgularıyla benzerlik göstermektedir. Algılanan hizmet kalitesi, bir hizmetin iyiliğinin veya kötülüğünün genel bir değerlendirmesidir (Twaissi \& Al-Kilani, 2015). Yüksek hizmet kalitesi sağlamak, sadece mevcut müşterileri elde tutmaya değil, aynı zamanda diğer paydaşlara, örneğin aday öğrenciler, işverenler, veliler, sponsorlar ve düzenleyiciler vb. tarafından verilen olumlu tavsiyelerin bir sonucu olarak yenilerini çekmeye de yardımcı olur (Ladhari, 2009; Negi, 2009). Bu, rekabetçi bir ortamda faaliyet gösteren üniversitelerin paydaşların ihtiyaçlarını karşılamak için nasıl yüksek kaliteli hizmet sunacaklarını düşünmek zorunda olmalarını gerektirir (DeShields Jr., Kara \& Kaynak, 2005). Bu bağlamda, öğrenci algılarına göre Türkiye'deki yükseköğretim kurumlarında hizmet kalitesinin yeterli düzeyde olmaması üniversitelerde bir kalite sorununa işaret edebilir.

Ayrıca boyutlar bazında, öğrenci algılarına göre yükseköğretim kurumlarının hizmet kalitesi incelendiğinde ise yükseköğretim kurumlarının akademik ve idari hizmetler ile kampüs olanaklarındaki kalitenin orta düzeyde olduğu sonucuna ulaşılmıştır. Boyutlar incelendiğinde; öğrenci algılarına göre yükseköğretim kurumlarının hizmet kalitesi düzeyi en yüksek boyut akademik hizmetler, en düşük boyut ise kampüs olanakları olmuştur. Yükseköğretim kurumlarındaki akademik ve idari hizmetler ile kampüs olanaklarının kalite bağlamında iyileştirmeye ihtiyaç duyduğu görülmektedir. Yükseköğretim kurumlarının kuruluşundaki önemli artış, yükseköğretim kurumlarında kalite sorunu ile sonuçlanmıştır (Abbas, 2020). Mok ve Jiang (2017), yükseköğretimin kitleselleşmesi nedeniyle, dünyanın dört bir yanındaki bazı yükseköğretim kurumlarının, öğrencilerin uygun eğitimi ve ilgili tesis ile donanımların mevcudiyeti gibi durumlarda kaliteden ödün verdiğini ifade etmiştir. Bu çerçevede, öğrenci algılarına göre Türkiye'deki yükseköğretim kurumlarında hizmet olanaklarının ve kalitesinin yeterli düzeyde olmaması artan üniversite sayısından kaynaklanabilir. Üniversitelerde, sayısal bağlamda artan nicelikle birlikte nitelikli bir yapının kurulması ve korunması da önemlidir. Araştırmanın ikinci alt problemi kapsamında; yükseköğretim kurumlarının hizmet kalitesi düzeyine ilişkin lisans öğrencisi algıları, bazı demografik değişkenlere (cinsiyet, sınıf) göre incelenmiştir.

Yükseköğretim kurumlarının hizmet kalitesi düzeyinde öğrencilerin cinsiyet değişkenine göre anlamlı bir farklılık olmadığı sonucuna ulaşılmıştır. Yükseköğretim kurumlarının hizmet 
kalitesi düzeyinde öğrencilerin cinsiyet değişkenine göre anlamlı bir farklılık olmadığına ilişkin araştırma bulgusu; Arakaya (2016) ve Özçelik (2018) tarafından yapılan araştırma bulgularıyla benzerlik göstermektedir.

Ayrıca boyutlar bazında, yükseköğretim kurumlarının idari hizmetler kalitesi düzeyinde öğrencilerin cinsiyet değişkenine göre anlamlı bir farklılık olduğu sonucuna ulaşılmıştır. Kız öğrenciler, erkek öğrencilere göre yükseköğretim kurumlarının idari hizmetler kalitesini daha yüksek bir düzeyde olduğunu belirtmiştir. Bu durum, kız öğrencilerin idari hizmetlerden daha fazla memnun olduklarını göstermektedir. Kız öğrencilerin memnuniyetleri, idari hizmetlerle daha çok iç içe olmalarından kaynaklanabilir. Yükseköğretim kurumlarının akademik hizmetler ve kampüs olanakları kalitesi düzeyinde öğrencilerin cinsiyet değişkenine göre anlamlı bir farklılık olmadığı sonucuna ulaşılmıştır.

Öğrencilerin yükseköğretim kurumlarının hizmet kalitesine ilişkin algılarının, sınıf değişkenine göre anlamlı bir şekilde farklılaştığı sonucuna ulaşılmıştır. Bu durum sınıfın, öğrencilerin yükseköğretim kurumlarının hizmet kalitesi algılarında farklı etkilere sahip olduğunu göstermektedir. Hazırlık sınıfı öğrencileri, daha üst sınıf öğrencilerine göre yükseköğretimde hizmet kalitesi düzeyini daha yüksek olarak belirtmiştir. Bu durum, hazırlık sınıfı öğrencilerinin yükseköğretim kurumlarındaki hizmet kalitesini daha yeterli gördüklerini ve bu hizmetlerden daha memnun olduklarını göstermektedir. Hazırlık sınıfı öğrencilerinin hizmetlere daha fazla ihtiyaç duyduğu, bu bağlamda hazırlık sınıfı öğrencileri beklentisinin belirli bir düzeyde karşılandığı müddetçe daha düşük ve kalite algısının daha olumlu olduğu ifade edilebilir. Öğrencilerin yükseköğretim kurumlarının hizmet kalitesine ilişkin algılarının, sınıf değişkenine göre anlamı bir şekilde farklılaştığına ilişkin araştırma bulgusu; Arakaya (2016) tarafından yapılan araştırma bulgularıyla benzerlik göstermektedir. Arakaya (2016) tarafından yapılan araştırmada da genel olarak hazırlık sınıfı öğrencileri, daha üst sınıf öğrencilerine göre yükseköğretim kurumlarının hizmet kalitesi düzeyini daha yüksek olarak belirtmiştir.

Ayrıca boyutlar bazında, öğrencilerin yükseköğretim kurumlarının akademik ve idari hizmetler ile kampüs olanakları kalitesine düzeyinde sınıf değişkenine göre anlamlı bir şekilde farklılaştığı sonucuna ulaşılmıştır. Bu durum sınıfın, öğrencilerin yükseköğretim kurumlarının akademik ve idari hizmetler ile kampüs olanakları kalitesi algılarında farklı etkilere sahip olduğunu gösterir. Genel bağlamda hazırlık sınıfı öğrencileri, daha üst sınıf öğrencilerine göre yükseköğretim kurumlarının akademik ve idari hizmetler ile kampüs olanaklarındaki kalite düzeyini daha yüksek olarak belirtmiştir. Bu durum, hazırlık sınıfı öğrencilerinin yükseköğretim kurumlarındaki akademik ve idari hizmetler ile kampüs olanaklarının kalitesinden daha memnun olduklarını göstermektedir. Hazırlık sınıfı öğrencilerinin yükseköğretim kurumuna adaptasyonu sürecinde akademik ve idari hizmetler ile kampüs olanaklarının yeterli ve nitelikli olmasına daha çok gereksinim duyduğu ifade edilebilir. 
Araştırma sonuçlarına ilişkin öneriler şunlardır:

- Yükseköğretim kurumlarındaki hizmet kalitesinin artırılması amacıyla YöK tarafından kalite ölçütleri geliştirilerek üniversiteler bu doğrultuda teşvik edilebilir.

- Yükseköğretim kurumlarındaki hizmetlerin daha kaliteli olması amacıyla idari ve akademik personele kalite standartlarına ilişkin eğitimler düzenlenebilir.

- Yükseköğretim kurumlarının her kademesinde hizmetlerin kaliteli olmasından taviz verilmeden, yeterli ve nitelikli bir hizmetin sağlanması amacıyla üniversitedeki tüm paydaşlar işbirliği içinde çalışabilir.

- Yükseköğretimde sadece nicelik olarak kurumların artırılmasıyla değil, nitelikli kurumların var olmasıyla hizmet kalitesi geliştirilebilir.

- Araştırmada, öğrenci algılarına göre yükseköğretim kurumlarının hizmet kalitesi düzeyi incelenmiştir. Benzer araştırmalar; yükseköğretim kurumlarının geliştirmesi beklenen "memnuniyet, doyum" gibi kavramlarla ilişkili şekilde gerçekleştirilebilir.

- Araştırma, nicel yönetimi esas almıştır. Benzer araştırmalar, yükseköğretim kurumlarının hizmet kalitesinin derinlemesine incelenmesi amacıyla, nitel ve karma yöntemler esas alınarak yapılabilir.

- Araştırmada, lisans öğrencileri örneklem olarak alınmıştır. Benzer araştırmalar, yükseköğretim kurumlarının hizmet kalitesinin genel görünümünün belirlenmesi amacıyla, akademik ve idari personel örneklem alınarak gerçekleştirilebilir. 


\title{
Examination of Service Quality of Higher Education Institutions According To University Student Perceptions
}

\author{
Muhammet İbrahim Akyürek*
}

\section{Introduction}

Ascertaining the quality of services provided by higher education institutions can guide universities to make further improvements. A cursory scan of the literature reveals that studies examining this area in a Turkish context are limited and generally restricted to a specific university or faculty. Consequently, there is a need to determine the status of service quality in higher education institutions in Turkey. Analyzing the situation of Turkish academic and administrative services and campus facilities with respect to service quality will provide a holistic perspective and fill in the extant gap in the literature. Accordingly, this study endeavors to determine the quality of services provided by higher education institutions in Turkey. Whereas previous studies gauged quality by the standards of their time, the current study employs an up-to-date scale (Çınkır, Yıldız, \& Kurum, 2021) that takes into account the quality standards of the ever-changing global atmosphere. Since customer satisfaction is one determinant of organizational success (Abbas, 2019; Campos, Santos, \& Castro, 2017) and students are the primary customers of higher education institutions, it is imperative that their satisfaction be ensured (Guilbault, 2018). Institution-wide student feedback on the quality of total educational experiences is an increasing field of activity in universities worldwide (Cardona \& Bravo, 2012; Zineldin, 2007). It is important to determine how students perceive the quality of services offered in higher education institutions, as they are the primary customers.

* Dr., Etimesgut Science and Art Center, Ankara/Turkey, i_akyurek56@hotmail.com, ORCID: 0000-0001-9122-471X 
Accordingly, this study aims to determine how university students perceive the quality of services provided by higher education institutions.

\section{Method}

The current study adopts a cross-sectional survey model. The universe consists of undergraduate students (primary education) attending state universities in Turkey during the 2020-2021 academic year. The sample is comprised of 460 undergraduate students (daytime education) attending state universities in Turkey during the 2020-2021 academic year. Participants were selected using simple random sampling. We used the Service Quality Scale in Higher Education developed by Çınkır, Yıldız, and Institution (2021) to gauge students' perceptions. Data were collected in June 2021 from 460 undergraduate students studying digital media. Owing to the ongoing pandemic, however, data could not be collected face to face.

\section{Discussion and Conclusion}

An evaluation of student perceptions demonstrates that, overall, they considered the quality of services provided by higher education institutions to be mediocre. This indicates that relevant services should be enhanced and that there is a need to develop a quality service understanding. Considering students' perceptions, service quality is inadequate. This finding is similar to those obtained by Arakaya (2016), Aygün (2015), Gerşil and Güven (2018), and Özçelik (2018). Perceived service quality is a general assessment of the character of a service provided (Twaissi \& AlKilani, 2015). It is important that high quality be insured not only to retain existing customers but also to attract prospective students, employers, parents, sponsors, and regulators (Ladhari, 2009; Negi, 2009) This obliges universities to consider how to deliver high quality service to meet the needs of stakeholders (Deshields Jr., Kara, \& Kaynak, 2005). Accordingly, the inadequacy of perceived service quality in Turkish higher education institutions indicates a problem in universities.

Though no significant difference in perceived service quality was found to exist by gender, one was found by class level. To increase the quality of services provided in higher education institutions, individual universities—or the Higher Education Council—can be encouraged to develop quality criteria and implement quality standard training at the administrative and faculty levels.

\section{Kaynakça/References}

- $\quad$ Abbas, J. (2019). Impact of total quality management on corporate sustainability through the mediating effect of knowledge management. Journal of Cleaner Production, 244, Article 118806.

- $\quad$ Abbas, J. (2020). Service quality in higher education institutions: Qualitative evidence from the students' perspectives using Maslow hierarchy of needs. International Journal of Quality and Service Sciences. DOI: 10.1108/IJQSS-02-2020-0016.

- $\quad$ Abbas, J., \& Sagsan, M. (2019). Identification of key employability attributes and evaluation of university graduates' performance: Instrument development and validation. Higher Education Skills and Workbased Learning, 10(3), 449-466. 
- Abili, K., Thani, F. N., \& Afarinandehbin, M. (2012). Measuring university service quality by means of SERVQUAL method. Asian Journal on Quality, 13, 204-211.

- $\quad$ Acer, E. K., \& Güçlü, N. (2017). An analysis of the expansion of higher education in turkey using the new institutional theory. Educational Sciences Theory \& Practice, 17(6), 1911-1933.

- $\quad$ Ali, F., Zhou, Y., Hussain, K., Nair, P. K., \& Ragavan, N. A. (2016). Does higher education service quality effect student satisfaction, image and loyalty? A Study of international students in malaysian public universities. Quality Assurance in Education, 24(1), 70-94.

- $\quad$ Arakaya, A. (2016). Yükseköğretimde hizmet kalitesi ölçümü: Öğrenci İşleri Daire Başkanlığı örneği. Yüksek Lisans Tezi. Karabük Üniversitesi Sosyal Bilimler Enstitüsü, Karabük.

- $\quad$ Aygün, M. S. (2014). Hizmet kalitesinin öğrenci memnuniyeti üzerindeki etkisi: Bitlis Eren Üniversitesi örneği. Yüksek Lisans Projesi. Kahramanmaraş Sütçü İmam Üniversitesi Sosyal Bilimler Enstitüsü, Kahramanmaraş.

- Brachem, J. C., \& Braun, E. M. P. (2018). Job-related requirements and competences of educational science graduates. Journal of Further and Higher Education, 42(2), 166-176.

- Brochado, A. (2009). Comparing alternative instruments for measuring service quality in higher education. Quality Assurance in Education, 17, 174-190.

- Büyüköztürk, Ş. (2013). Sosyal bilimler için veri analizi el kitabı. Ankara: Pegem.

• Büyüköztürk, Ş., Çakmak, E. K., Akgün, Ö. E., Karadeniz, Ş., \& Demirel, F. (2012). Bilimsel araştırma yöntemleri. Ankara: Pegem.

- Campos, D. F., Santos, G. S. D., \& Castro, F. N. (2017). Variations in student perceptions of service quality of higher education institutions in Brazil: A longitudinal study. Quality Assurance in Education, 25(4), 394-414.

- Cardona, M., \& Bravo, J. (2012). Service quality perceptions in higher education institutions: The case of a Colombian University. Estudios Gerenciales, 28, 23-29.

- Churchill, G., \& Surprenant, C. (1982). An investigation into the determinants of customer satisfaction. J Mark Res, 19, 491-504.

- Cronin, J. J., \& Taylor, S. A. (1992). Measuring service quality: A reexamination and extension. Journal of Marketing, 55-68.

- Çınkır, Ş., Yıldız, S., \& Kurum, G. (2021). Yükseköğretimde hizmet kalitesi ölçeğinin geliştirilmesi: Geçerlik ve güvenirlik çalışması. Yükseköğretim Dergisi, 11(1), 161-173.

- Deshields Jr., O. J., Kara, A., \& Kaynak, E. (2005). Determinants of business student satisfaction and retention in higher education: Applying herzberg's two-factor theory. International Journal of Educational Management, 19, 128-139.

- Doherty, G. D. (2008). On quality in education. Quality Assurance in Education, 16, 255-265.

- Donald, J. G., \& Denison, D. B. (2001). Quality assesment of university students: Student perceptions of quality criteria. The Journal of Higher Education, 72(4), 478-502.

- Eshghi, A., Roy, S., \& Ganguli, S. (2008). Service quality and customer satisfaction: An empirical investigation in Indian mobile telecommunications services. The Marketing Management Journal, 18, 119-144.

- Firdaus, A. (2005). HEDPERF versus SERVPERF the quest for ideal measuring instrument of service quality in higher education sector. Quality Assurance in Education, 13(4), 305-328.

- George, D., \& Mallery, M. (2010). SPSS for Windows step by step: A simple guide and reference, 17.0 update (10th ed.). Boston, MA: Pearson.

- Gerşil, M., \& Güven, H. (2018). Üniversitelerde hizmet kalitesinin SERVQUAL analizi ile ölçülmesi: Celal Bayar Üniversitesi'nde bir uygulama. Ömer Halisdemir Üniversitesi İktisadi ve İdari Bilimler Fakültesi Dergisi, 11(1), 111-125. 
- Gravetter, F. J., \& Wallnau, L. B. (2000). Statistics for the behavioral Sciences (5th ed.). Belmont, CA: Wadsworth/Thomson Learning.

- Guilbault, M. (2018). Students as customers in higher education: The (Controversial) debate needs to end. Journal of Retailing and Consumer Services, 40(1), 295-298.

- Gürbüz, S., \& Şahin, F. (2014). Sosyal bilimlerde araştırma yöntemleri: Felsefe-yöntem-analiz. Ankara: Seçkin.

- $\quad$ Habib, M., Abbas, J., \& Noman, R. (2019). Are human capital, intellectual property rights, and research and development expenditures really important for total factor productivity? An empirical analysis. International Journal of Social Economics, 46(6), 756-774.

- $\quad$ Hair, J. F., Ringle, C. M., \& Sarstedt, M. (2011). PLS-SEM: Indeed a silver bullet. Journal of Marketing, The oryand Practice, 19(2), 139-152.

- Imran, M., \& Abbas, J. (2020). The role of strategic orientation in export performance of China automobile industry. Handbook of Research on Managerial Practices and Disruptive Innovation in Asia, IGI Global, pp. 249-263.

- $\quad$ İçli, G. E., \& Vural, B. B. (2010). Toplam kalite yönetimi ve uygulamaları çerçevesinde Kırklareli Üniversitesi meslek yüksekokulları öğrenci memnuniyeti araştırması. Marmara Üniversitesi I.İ.B.F. Dergisi, 28(1), 335-349.

- $\quad$ İçli, G., \& Anıl, N. (2014). The HEDQUAL scale: A new measurement scale of service quality for MBA programs in higher education. South African Journal of Business Management, 45, 31-43.

- $\quad$ Jupiter, H., Othman, I. W., Suki, N. M., Yusoff, M. S., Awang, H., \& Razak, R. A. (2017). Factors influencinng international student's decision in choosing study destination abroad. Labuan E-Journal of Muamalat and Society, 11(1), 86-97.

- $\quad$ Karasar, N. (2015). Bilimsel araştırma yöntemi: kavramlar, ilkeler, teknikler. Ankara: Nobel.

- $\quad$ Khodayari, F., \& Khodayari, B. (2011). Service quality in higher education. Interdisciplinary Journal of Research in Business, 1, 38-46.

- Ladhari, R. (2009). Service quality, emotional satisfaction, and behavioural intentions: A study in the hotel industry. Managing Service Quality: An International Journal, 19, 308-331.

- Lapina, I., Roga, R., \& Müürsepp, P. (2016). Quality of higher education: International students' satisfaction and learning experience. Int J Qual Serv Sci, 8, 263-278.

- $\quad$ Li, W. (2018). Research on the innovative development mode of quality education of college students based on the perspective of human resource management. Educational Sciences Theory \& Practice, 18(5), 2447-2454.

- Liu, S. (2016). Higher education quality assessment and university change: A theoretical approach. In S. Liu (Ed.), Quality assurance and institutional transformation (pp. 15-46). Singapore: Springer. https:// doi.org/10.1007/978-981-10-0789-7_2.

- $\quad$ Modestino, A.S., Shoag, D., \& Ballance, J. (2016). Downskilling: Changes in employer skill requirements over the business cycle. Labour Economics, 41, 333-347.

- Mok, K. H., \& Jiang, J. (2017). Massification of higher education and challenges for graduate employment and social mobility: East asian experiences and sociological reflections. International Journal of Educational Development, 63(1), 44-51

- Moslehpour, M., Chau, K. Y., Zheng, J., Hanjani, A. N., \& Hoang, M. (2020). The mediating role of international student satisfaction in the influence of higher education service quality on institutional reputation in Taiwan. International Journal of Engineering Business Management, 12, 1-16.

- Negi, R. (2009). Determining customer satisfaction through perceived service quality: A study of Ethiopian mobile users. International Journal of Mobile Marketing, 4, 31. 
- $\quad$ Özçelik, Y. (2018). Yabancı diller yüksek okulu hazırlık bölümü öğrencilerinin yükseköğretimde hizmet kalitesi ve üniversiteye güven algıları. Yüksek Lisans Tezi. Abant İzzet Baysal Üniversitesi Eğitim Bilimleri Enstitüsü, Bolu.

- Parasuraman, A., Zeithaml, V., \& Berry, L. (1985). A conceptual model of service quality and its implications for future research. The Journal of Marketing, 49, 41-50.

- Parasuraman, A., Zeithaml, V., \& Berry, L. (1988). Servqual: A multiple-item scale for measuring consumer perceptions of service quality. Journal of Retailing, 64, 12.

- $\quad$ Premand, P., Brodmann, S., Almeida, R., Grun, R., \& Barouni, M. (2016). Entrepreneurship education and entry into self-employment among university graduates. World Development, 77, 311-327.

- $\quad$ Roser, M., \& Ortiz-Ospina, E. (2018). "World population growth." OurWorldInData.ORg. 2018. https:// ourworldindata.org/world-population-growth.

- Saydan, R. (2008). Üniversite öğrencilerinin öğretim elemanlarından kalite beklentileri: Yüzüncü Yll Üniversitesi İïBF örneği. Gazi Üniversitesi İktisadi ve İdari Bilimler Fakültesi Dergisi, 10(1). 63-79.

- Shahzad, M., Ying, Q., Rehman, S., Zafar, A., Ding, X., \& Abbas, J. (2019). Impact of knowledge absorptive capacity on corporate sustainability with mediating role of CSR: Analysis from the Asian context. Journal of Environmental Planning and Management, 63(2), 148-174.

- Tholen, G., Relly, S. J., Warhurst, C., \& Commander, J. (2016). Higher education, graduate skills and the skills of graduates: The case of graduates as residential sales estate agents. British Educational Research Journal, 42(3), 508-523.

- $\quad$ Truong, H. V., Pham, C. H., \& Vo, N. H. (2016). Service quality and students level of satisfaction in private colleges in Vietnam. International Journal of Financial Research, 7(3), 121-128.

- Türeli, N. \& Aytar, O. (2014). Meslek Yüksekokulu eğitiminde hizmet kalitesinin SERVQUAL yöntemi ile ölçümü: Karamanoğlu Mehmet Bey Üniversitesinde bir uygulama. Akademik Bakış Dergisi, 43, 1-15.

- Twaissi, N. M., \& Al-Kilani, M. H. (2015). The impact of perceived service quality on students intentions in higher education in a Jordanian Government University. International Business Research, 8, 81-92.

- Van Schalkwyk, R. D., \& Steenkamp, R. J. (2014). The exploration of service quality and its measurement for private higher education institutions. Southern African Business Review, 18, 83-107.

- Van Schalkwyk, R. D., \& Steenkamp, R. J. (2016). The exploration of service quality leadership for private higher education institutions in South Africa. JHEA/RESA, 14(2), 85-105.

- Watty, K. (2006). Want to know about quality in higher education? Ask an academic. Quality in Higher Education, 12(3), 291-301.

- Willms, W., Kenzie, O., McAllister, T., vd. (2006). Effects of water quality on cattle performance. J Range Manag, 55, 452-460.

- YÖK (2021). 2019-2020 Öğretim Yll İstatistikleri. https://istatistik.yok.gov.tr/ sayfasından erişilmiştir.

- Yllmaz, V., Filiz, Z., \& Yaprak, B. (2007). SERVQUAL yöntemi ile yükseköğretimde hizmet kalitesinin ölçülmesi. Anadolu Üniversitesi Sosyal Bilimler Dergisi, 7(1), 299-316.

- Zafiropoulos, C., \& Vrana, V. (2008). Service quality assessment in a Greek higher education institute. Journal of Business Economics and Management, 9, 33-45.

- Zineldin, M. (2007). The quality of higher education and student satisfaction self-assessment and review process a term philosophy and $5 \mathrm{Q}$ s model. Paper presented at 2nd International conference Education, Economics, and Law: Traditions and Innovations, Vaxjo University, Sweden.

- Zineldin, M., Akdag, H., \& Vasicheva, V. (2011). Assessing Quality in Higher Education: New Criteria for Evaluating Students' Satisfaction. Quality in Higher Education, 17, 231-243. 